\title{
Testosterone Replacement Therapy in Hypogonadal Men Following Prostate Cancer Treatment: A Questionnaire-Based Retrospective Study among Urologists in Bavaria, Germany
}

\author{
Charlotte Marie Kühn $^{\mathrm{a}}$ Hans Strasser ${ }^{\mathrm{b}} \quad$ Alexander Romming ${ }^{\mathrm{a}}$ Bernd Wullich $^{\mathrm{a}}$ \\ Peter J. Goebella \\ ${ }^{a}$ Department of Urology, Friedrich Alexander University Erlangen-Nürnberg, Erlangen, and ${ }^{\text {b Urologische }}$ \\ Gemeinschaftspraxis, Nürnberg, Germany
}

\section{Key Words}

Testosterone replacement therapy · Prostate cancer .

Hypogonadal men

\begin{abstract}
Background: Several reports suggest testosterone replacement therapy (TRT) may be an option in selected hypogonadal patients with a history of prostate cancer ( $\mathrm{PCa}$ ) and no evidence of disease after curative treatment. Our aim was to assess TRT experience and patient management among urologists in Bavaria. Materials and Methods: Questionnaires were developed and mailed to all registered urologists in Bavaria $(n=420)$ regarding their experience with TRT in patients with treated PCa. Results: One hundred and ninety-three (46\%) urologists returned the questionnaire and reported their experience with TRT in hypogonadal patients after curative treatment for PCa. Complete data was available for 32 men. Twenty-six patients (81\%) received TRT after prostatectomy, 1 patient after external beam radiation, 3 patients after high-dose brachytherapy and 2 patients after high-intensity focused ultrasound. Of the PCa cases, $88.5 \%$ $(23 / 26)$ were organ confined (pT2a-c), and 3 were pT3 tumors. All patients were $\mathrm{pNO} / \mathrm{cNO}$, and only 1 patient (pT3a) had a positive surgical margin status postoperatively. After
\end{abstract}

a mean follow-up of 39.8 months, no biochemical relapse was observed. Conclusion: To date, there is no clear evidence to withhold TRT from hypogonadal men after curative PCa treatment. Our findings, although with limitations, fit in with the available data showing that TRT does not put patients at an increased risk after curative treatment of PCa.

(c) 2015 S. Karger AG, Basel

\section{Introduction}

Late onset hypogonadism ( $\mathrm{LOH}$ ) is frequently found in men $>40-50$ years and is often accompanied by clinical symptoms such as loss of vigor, lethargy, depressive mood, alterations in body composition (increase in fat mass, decrease in lean body mass), reduced bone mineral density, metabolic syndrome, hot flashes, loss of libido and erectile dysfunction [1].

Prostate carcinoma (PCa) is the most common malignant disease in men, with many of them undergoing curative therapies such as radical prostatectomy, external radiation therapy or brachytherapy, offering the overwhelming majority of them long-term survival without tumor progress. Because $\mathrm{PCa}$ is a typical disease of elderly men, with a culmination in the 7 th decade, a substantial number

\section{KARGER 125}

(c) 2015 S. Karger AG, Base

$0042-1138 / 15 / 0952-0153 \$ 39.50 / 0$

E-Mail karger@karger.com

www.karger.com/uin
Charlotte Marie Kühn

Department of Urology, Friedrich Alexander University Erlangen-Nürnberg Krankenhausstrasse 12

DE-91054 Erlangen (Germany)

E-Mail charlotte-kuehn@gmx.de 
of these men are diagnosed with $\mathrm{LOH}$ after curative treatment of PCA, prompting them to present at a urologist's office because of LOH-related clinical symptoms.

The link between testosterone and PCa comes from a landmark study by Huggins and Hodges [2], which admittedly included only a few patients with bone metastases from PCa. Because this study provided evidence that testosterone deprivation resulted in a decrease in both acid phosphatase and clinical symptoms of $\mathrm{PCa}$, whereas testosterone supplementation had the opposite effect, testosterone replacement therapy (TRT) for hypogonadism has long been associated with the risk of a development of PCa and has therefore been considered dangerous on a long-term basis. Furthermore, TRT in hypogonadal men with a history of $\mathrm{PCa}$, even without any evidence of biochemical progress, has been and is currently widely considered a 'no go' in the medical domain. Recent studies aiming at investigating the intraprostatic androgen metabolism, however, have further added to our knowledge in this field. In summary, there is a growing body of evidence that testosterone impacts PCa growth only in the very low near-castrate range threshold serum testosterone concentrations because of the complete saturation of the androgen receptors (ARs) through which the biological effects of testosterone are mediated (saturation point) [3]. Because the number of these ARs is limited, no further testosterone-related effects can be mediated if all of them are occupied by -testosterone molecules, i.e. after the AR saturation capacity has been reached. Serum testosterone levels beyond this cutoff concentration for AR saturation can therefore not add any biological effects to the benign or malignant growth of prostate cells. Based on this AR saturation theory, correction of serum testosterone in hypogonadal men can neither induce nor promote PCa growth because the AR saturation capacity is reached at serum testosterone concentrations far below the levels reached with TRT [4].

In addition, some PCa cohort series discussed a negative correlation between serum testosterone level and $\mathrm{PCa}$ risk. Men with low serum testosterone levels have been reported to suffer more frequently from $\mathrm{PCa}[5]$ and from more aggressive PCa with higher progression rates $[6,7]$.

Because hypogonadism causing clinical symptoms in elderly men after curative treatment for PCa is an increasing problem in the urological practice, the question whether these patients are put on an increased risk for PCa relapse while on TRT becomes relevant for many urologists.

There is no question that until now a widespread uncertainty has existed within the urologic community, especially because no prospective studies are available in- vestigating this problem. Thus, this questionnaire-based trial was initiated to assess the current practice regarding the management of hypogonadal men after treatment of $\mathrm{PCa}$ in urology offices and clinics. For this purpose, we developed a short and easy-to-answer questionnaire, which contained 7 relevant questions on the current use of TRT. In order to obtain the most representative assessment, all registered urologists in Bavaria were approached.

A clear focus of the project was to (a) survey the use and practice of TRT among urologists in Bavaria and (b) analyze the fate and features of the individual patients eventually treated with TRT.

\section{Patients and Methods}

In summary, questionnaires were mailed to 420 urologists with a return rate of 193 (46\%), comprising information on all in all 36 patients who were treated with TRT. For the analyses, we included only those patients of whom the complete data set (each item of the questionnaire) was available. Thus, 4 patients were excluded due to incomplete or inconsistent data. All registered urologists practicing in Bavarian clinics and offices $(n=420)$ were contacted via mailings. In the accompanying questionnaire, they were asked to share their experience with TRT in hypogonadal men in general and in those after PCa treatment. The questionnaire consisted of 7 questions:

(1) Do you have any experience with TRT in men with (a) a confirmed diagnosis of hypogonadism and (b) after prostate cancer? Only if the urologist answered yes, a detailed description of the patients' characteristics and treatment was requested.

(2) Questions on the clinical and pathologic PCa status [cT stage, pT stage, R status, lymph node involvement, Gleason score, prostate-specific antigen (PSA; initial and prior to substitution of testosterone)], timing of TRT and age at its beginning.

(3) What were the reasons for the initiation of the TRT?

(4) What mode of TRT was chosen?

(5) When was PSA controlled after the initiation of the TRT?

(6) If there was a rise in PSA, what was its highest level?

(7) If there was a rise in PSA, for what reason was TRT stopped?

The questionnaires were evaluated and, if necessary, completed by additional contact with the physicians. According to the concurrent S3 guidelines for PCa management of the Deutsche Gesellschaft für Urologie (i.e. the German Association of Urology), biochemical progress was defined by a PSA value of $>0.2 \mathrm{ng} / \mathrm{ml}$, confirmed at least twice after radical prostatectomy, and by a rise in the PSA level of $>2 \mathrm{ng} / \mathrm{ml}$ over the nadir after radiation therapy, confirmed at least twice.

\section{Results}

Of a total of 420 Bavarian urologists contacted, 193 (46\%) returned the questionnaire. One hundred and seventy urologists shared their general experience with TRT 
in hypogonadal men, which translates into $88 \%$ of all colleagues having some kind of experience with TRT. Thus, the perception that hormone replacement is an uncommon subject cannot be regarded as correct. Obviously, the vast majority of urologists are at least aware of this issue, making it a relevant topic for further investigations and education. Thirty urologists (18\%) used TRT in 43 hypogonadal patients, all of whom had had previous therapy for PCa with curative intent. Of these patients, complete data were available for 32. No urologist applied TRT in a patient with untreated PCa. The baseline characteristics of the TRT study population are shown in tables 1 and 2 . Transdermal gel was the most frequent form of application (22 patients, 69\%). Thirteen patients (41\%) received intramuscular depot injections. Oral supplementation was chosen in 1 patient only. In 4 patients, transdermal gel and an intramuscular formulation were combined. The mean patient age at the initiation of the TRT was 65.6 years (range 51-80 years). Twenty-six patients (81\%) received TRT after radical prostatectomy, 1 patient $(3 \%)$ after external beam radiation therapy, 3 patients (9\%) after high-dose brachytherapy and 2 patients (6\%) after high-intensity focused ultrasound. The mean follow-up since the initiation of the TRT was 39.8 months (range 12-108 months). Regarding the tumor stage at radical prostatectomy, $88.5 \%(23 / 26)$ of the PCas were organ confined (pT2a-c), and 3 were pT3 tumors. All patients were $\mathrm{pN} 0$ or $\mathrm{cN} 0$, and there was only 1 patient (pT3a) with a positive surgical margin postoperatively. Two of the 3 patients with pT3 tumors underwent plastic orchiectomy immediately after prostatectomy. Of the 6 patients receiving radiation therapy or high-intensity focused ultrasound, 5 were cT2 and 1 was cT3a. Regarding the tumor grade, 28 out of the 32 patients $(87.5 \%)$ had a Gleason score of $\leq 7$. The mean initial serum PSA before PCa treatment was $7.7 \mathrm{ng} / \mathrm{ml}$ (range $0-26 \mathrm{ng} / \mathrm{ml}$ ), and the mean at the initiation of TRT was $0.17 \mathrm{ng} / \mathrm{ml}$ (range $0-4.37 \mathrm{ng} / \mathrm{ml}$ ). The average time interval between the definitive initial PCa therapy and the onset of TRT was 31.2 months (range 2-108 months). In 29 patients (91\%), TRT was performed because of clinical symptoms and a decreased serum total testosterone level. In 3 patients, a decreased total testosterone level was the only indication for TRT. The most frequent clinical symptoms were depressive mood (72\%), loss of libido (72\%), decreased muscle mass (69\%), fatigue (69\%), erectile dysfunction (53\%) and sleeping disorders (31\%). Before the onset of TRT, testosterone levels were between 0.1 and $319 \mathrm{ng} / \mathrm{dl}$. The time interval of the follow-up examinations after the initiation of the TRT was 2.85 months (range 1-6 months).
Table 1. Baseline PCa and treatment characteristics of the 32 patients

\begin{tabular}{ll}
\hline Features & Overall patients $(\mathrm{n}=32)$ \\
\hline Age, years & $65.6(51-80)$ \\
Treatment, $\mathrm{n}$ & 26 \\
$\quad$ Prostatectomy & 3 \\
$\quad$ Brachytherapy & 1 \\
$\quad$ External beam radiotherapy & 2 \\
$\quad$ High-intensity focused ultrasound & \\
PSA level, ng/ml & $7.66(0-26)$ \\
$\quad$ Before treatment of PCa & $0.17(0-4.37)$ \\
$\quad$ Before onset of TRT & $70.8(0.1-319)$ \\
Testosterone level before TRT, ng/dl & $3.36(0.25-9)$ \\
Duration of TRT, years & \\
Interval of follow-up examinations, & $2.85(1-6)$ \\
$\quad$ months &
\end{tabular}

Data represent numbers or medians with ranges in parentheses.

Table 2. Tumor characteristics

\begin{tabular}{lc}
\hline Features & Overall patients $(\mathrm{n}=32)$ \\
\hline Biopsy Gleason score before primary treatment \\
$\leq 6$ & 20 \\
$3+4$ & 8 \\
$\geq 8$ & 4 \\
Pathologic stage after prostatectomy & \\
T2a & 14 \\
T2b & 5 \\
T2c & 4 \\
T3a & 1 \\
T3b & 2 \\
Clinical stage before radiotherapy/HIFU & \\
T1a & 2 \\
T1b & 1 \\
T1c & 1 \\
T2c & 1 \\
T3a & 1 \\
Nodal stage & \\
cN0/pN0 & 32 \\
Margin status after prostatectomy & \\
R0 & 25 \\
R1 & 1
\end{tabular}

HIFU = High-intensity focused ultrasound.

None of the 32 patients suffered from a biochemical recurrence and/or progression. During TRT, the mean increase in PSA was $0.01 \mathrm{ng} / \mathrm{ml}$ (range $0-0.11 \mathrm{ng} / \mathrm{ml}$ ) after prostatectomy and $0.23 \mathrm{ng} / \mathrm{ml}$ (range $0-1.1 \mathrm{ng} / \mathrm{ml}$ ) after radiotherapy. Therapy was discontinued in 7 patients 
(22\%): in 4 cases $(13 \%)$ due to a cessation of the symptoms, in 1 case (3\%) due to persistent symptoms, in another case (3\%) at the patient's request and in 1 case because of a rise in PSA of $0.1 \mathrm{ng} / \mathrm{ml}$.

\section{Discussion}

Since the publication by Huggins and Hodges [2], PCa has been regarded as androgen sensitive. Following this cornerstone discovery, androgen deprivation therapy has become the mainstay treatment for men with advanced PCa. One of the pharmacological agents first described to suppress serum testosterone and to be an alternative to surgical castration was diethylstilbestrol. After 8 decades of clinical utility and despite new therapeutic options prior to chemotherapy (e.g. abiraterone, enzalutamide, orteronel, immunotherapy and targeted therapies), the applicability of diethylstilbestrol may be still considered, as a very recent publication suggested [8]. Since testosterone suppression is regarded as a therapeutic option, testosterone supplementation is seen as contraindicated for patients with PCa because androgen depletion is meant to reduce tumor growth, whereas testosterone may support tumor progression. In fact, recent investigations on the association of pretreatment serum total testosterone could demonstrate in a population of 220 patients prior to radical prostatectomy that increased pretreatment serum measurements of total testosterone are associated with and functionally related to a high-grade pathologic Gleason score [9]. Moreover, baseline total testosteron together with the Gleason score at biopsy and PSA were important factors for predicting a pathologic Gleason score and assessing high-grade tumors. These findings appear to support the possible role of high testosterone levels for the promotion of more aggressive phenotypes of prostate tumors. This theory was questioned for the first time in 1981 by Fowler and Whitmore [10]. The authors described a surprising finding in patients who harbored metastatic PCa and who were treated with exogenous testosterone: the progression rate 30 days after the initiation of the treatment differed substantially in the various subgroups. Only $25 \%$ of the treatment-naïve patients, $36 \%$ of patients with a remission during androgen deprivation therapy and $94 \%$ of patients who had progression of their disease during hormonal therapy experienced progression.

However, the role of hormonal status and thus the relevance of the 'phase' of the disease were not re-evaluated until recently. A meta-analysis from 18 studies with a to- tal number of 3,886 men with PCa and 6,438 men without detectable disease did not reveal a correlation between testosterone levels in the blood and an increased risk for PCa [11]. In a randomized trial by Marks et al. [12], serum testosterone levels went back to normal after 6 months of TRT in 44 men with LOH. In addition, this did not significantly alter intraprostatic concentrations of androgens, other tissue-related biomarkers or expression of related genes. Consequently, Morgentaler [3,4] developed the saturation model. This model is based on the observation that PCa growth is highly sensitive to variations in serum testosterone concentration at or below the nearcastrate level but is insensitive to a rise of testosterone above this concentration. Interestingly, the risk of PCa is significantly higher $(21 \%)$ in hypogonadal men (testosterone $<250 \mathrm{ng} / \mathrm{dl}$ ) than in men with testosterone levels of $>250 \mathrm{ng} / \mathrm{dl}$ (12\%) [5]. In addition, there is a significant correlation between lower serum testosterone levels and the incidence of high-risk PCa $[6,7]$.

These findings have led to a growing interest in elucidating the role of testosterone within the AR signaling pathway, with an increased focus on the intraprostatic androgen levels and functions [13]. The prostate is both an androgen-dependent and an androgen-sensitive organ, and active processes are triggered at a threshold or saturation level of testosterone [14]. Normal prostate development is androgen dependent, requiring not only testosterone, but also the activity of the $5 \alpha$-reductase enzymes which convert testosterone to the more potent androgen dihydrotestosterone (DHT) [15]. DHT binds to ARs and causes a dissociation of heat shock proteins, allowing a translocation of the DHT-AR complex into the nucleus, where it binds to AR elements. Recruitment of coactivator proteins enables a transcriptional activation of target genes [16]. The prostate expresses high levels of type II 5a-reductase $[17,18]$ and enzymes involved in steroid metabolism $[19,20]$; therefore, the endocrine milieu within the prostate may substantially differ from that of the serum. In fact, very low levels of serum testosterone may be sufficient to maintain a sufficient intraprostatic milieu of androgens [21]. Interestingly, the most recent finding that testosterone may not be the primary source of intraprostatic DHT even adds further fuel to the debate on our understanding of the role of the interplay of the various androgens in and outside the prostate [22].

In summary, the current findings lead to the question of whether patients with PCa treated with curative intent who are 'free of measurable disease' and who have symptomatic hypogonadism could receive exogenous testos- 
Table 3. Reports addressing the effect of TRT in hypogonadal men with PCa treatment with curative intent

\begin{tabular}{|c|c|c|c|c|c|c|}
\hline Authors & $\begin{array}{l}\text { Patients, } \\
\mathrm{n}\end{array}$ & $\begin{array}{l}\text { Primary } \\
\text { therapy }\end{array}$ & $\begin{array}{l}\text { PSA level before } \\
\text { TRT, ng/ml }\end{array}$ & $\begin{array}{l}\text { Start of TRT after PCa } \\
\text { treatment, months }\end{array}$ & $\begin{array}{l}\text { Follow-up, } \\
\text { months }\end{array}$ & Cases of BCR \\
\hline $\begin{array}{l}\text { Kaufmann and } \\
\text { Graydon [23], } 2004\end{array}$ & 7 & $\mathrm{RP}$ & mean: $<0.1$ & mean: $33(0-108)$ & $\begin{array}{l}\text { mean: n.r. } \\
(12-144)\end{array}$ & none \\
\hline $\begin{array}{l}\text { Agarwal and } \\
\text { Oefelein [24], } 2005\end{array}$ & 10 & $\mathrm{RP}$ & mean: $<0.1$ & n.r. & $\begin{array}{l}\text { mean: } 19 \\
(9-29)\end{array}$ & none \\
\hline $\begin{array}{l}\text { Nabulsi et al. [26], } \\
2008\end{array}$ & 22 & $\mathrm{RP}$ & mean: $<0.1$ & $\begin{array}{l}\text { mean: } 26 \pm 35 \\
(2.5-118)\end{array}$ & $\begin{array}{l}\text { median: } 20 \\
(14-30)\end{array}$ & $1 / 22$ \\
\hline $\begin{array}{l}\text { Khera et al. [27], } \\
2009\end{array}$ & 57 & $\mathrm{RP}$ & n.r. & mean: $36(1-136)$ & $\begin{array}{l}\text { mean: } 13 \\
(1-99)\end{array}$ & none \\
\hline $\begin{array}{l}\text { Morales et al. [30], } \\
2009\end{array}$ & 5 & EBRT & mean: $<0.3$ & n.r. & $\begin{array}{l}\text { mean: } 14.6 \\
(6-27)\end{array}$ & $\begin{array}{l}\text { none (according to } \\
\text { ASTRO criteria) }\end{array}$ \\
\hline Sarosdy [28], 2007 & 31 & $\begin{array}{l}\text { brachytherapy } \\
\text { (with or without } \\
\text { EBRT) }\end{array}$ & mean: $<0.1$ & n.r. & $\begin{array}{l}\text { median: } 16 \\
(18-108)\end{array}$ & $\begin{array}{l}\text { PSA }<0.1 \text { in } 74 \% ; \\
\text { PSA }<1.0 \text { in } 100 \%\end{array}$ \\
\hline $\begin{array}{l}\text { Isbarn et al. [36], } \\
2010\end{array}$ & 69 & $\mathrm{RP}$ & $<0.1$ & median: 24 & $\begin{array}{l}\text { median: } 19 \\
(6-72)\end{array}$ & none \\
\hline $\begin{array}{l}\text { Leibowitz et al. [31], } \\
2010\end{array}$ & 96 & $\begin{array}{l}\text { RP: } 24 \text {; EBRT: } 12 \text {; } \\
\text { brachytherapy: } 1 \text {; } \\
\text { ADT: } 59\end{array}$ & median: 0.1 & n.r. & $\begin{array}{l}\text { median: } 36.7 \\
(2-9)\end{array}$ & $41 / 96$ \\
\hline
\end{tabular}

ADT = Androgen deprivation therapy ASTRO = American Society for Therapeutic Radiation Oncology; BCR = biochemical recurrence; $\mathrm{EBRT}$ = external beam radiotherapy; HIFU = high-intensity focused ultrasound; n.r. = not reported; $\mathrm{RP}=$ radical prostatectomy.

terone and if these measures implicate any additional attributable risk.

Until today, the number of investigations has been limited ( $\mathrm{n}=11)$, and the total number of patients included is low $(n=351$; table 3$)$. Seven trial reports have included more than 200 patients with TRT after radical prostatectomy [23-28], and 4 trials report testosterone substitution after radiation [25-27, 29-31]. Although the time of initiation of TRT differed substantially between the studies, ranging from immediately after surgery to 14 years after prostatectomy or radiation therapy, as did the follow-up times (from 1 month to 12 years), all but 1 study agreed that there was no increase in cancer recurrence with TRT in men who had been treated for PCa compared to men without TRT. Only 1 patient harboring a Gleason score $8 \mathrm{PCa}$ had a rise in PSA 17 months after TRT had been initiated [25]. Only Leibowitz et al. [31] observed a PSA progression in $43 \%$ of their patients. However, his cohort was very heterogeneous, with only 33 of 94 patients having a Gleason sum below 7 and with 
59 patients treated with androgen deprivation therapy alone.

Two trials investigated patients on 'active surveillance'. Morgentaler et al. [32] observed 13 patients with known PCa, who were treatment naïve and had clinically significant hypogonadism during TRT for a median of 2.5 years, and did not find a single example of local or systemic progress. Morales [33] reported on 7 men with untreated PCa and hypogonadism on TRT, 5 of whom had low-risk disease. The report describes 4 different PSA scenarios, 1 stable course and 3 distinct profiles of progression. Thus, Morales [33] advises others to be cautious and advocates for an international registry to identify risk factors relevant for hormonal treatment in men with PCa. The guidelines of the European Association of Urology [34] on male hypogonadism see PCa as a contraindication for testosterone substitution. However, the use of TRT in hypogonadal men with a history of PCa without evidence of progression should be re-evaluated. In the majority of previous studies, the available number of patients is limited, and the follow-up is too short. There is a lack of randomized controlled trials. For men with surgically treated localized PCa without evidence of progression and a clinically significant testosterone deficiency, TRT may be 'cautiously considered'. However, it must be noted that this would be an 'off-label' use. The therapy should only be considered for patients with low-risk disease and should be initiated, at the earliest, 1 year after surgery. A similar recommendation is given for patients treated with brachytherapy and external radiation.

What does this questionnaire-based analysis add? Despite the general awareness of hormone replacement therapy among the vast majority of urologists who answered the questionnaire, reflecting the relevance of this topic, the number of urologists with experience in providing TRT after PCa was as low as 18\%. Although the number of patients of whom detailed information was available appears small, it mirrors the current literature. This discrepancy underlines the current obstacle to obtain informative data which may eventually alter clinical practice. Apparently, despite the concern of those who provide this treatment, there was a high rate of incomplete or insufficient documentation. Consequently, this lack led to only 32 patients being eligible and considered in this analysis. Obviously, this could be interpreted as a lack of standards or at least of common recommendations on how TRT should be performed and thus documented. The analyses of this limited number of treatments can only be interpreted with caution. However, some findings are noteworthy when TRT is provided: the vast majority of patients had a localized disease, and none had any lymph node involvement. All but 1 patient had tumorfree surgical margins, and only 4 patients had an initial Gleason score of 8 or above. This may be due to the perception that TRT only appears to be safe in 'cured' patients. In addition, those patients who received the treatment obviously had a longer benefit, since the median duration of TRT was 3.36 years.

Overall, the experience from this investigation and the reports from other results looking at TRT in hypogonadal men after PCa treatment with curative intent are encouraging. As in the current literature, also in this cohort none of the 32 patients suffered a biochemical recurrence and/or progression.

However, there are some limitations to our TRT study population. As in all other reports, the number of cases was low; analysis took place retrospectively and was not controlled or randomized. The fact that only 193 (46\%) of 420 urologists responded to our request and that from the group of 170 urologists who shared their general experience with TRT, only $18 \%$ reported experience with TRT in men after PCa treatment with curative intent reflects the present uncertainty on the issue. Obviously, additional larger and prospective studies (e.g. prospective registry) are required to pinpoint tumor characteristics and the appropriate time frame for the initiation of TRT after PCa therapy in hypogonadal men.

\section{Conclusions}

TRT in hypogonadal men after PCa treatment with curative intent used to be clearly contraindicated and is still considered off-label use. However, TRT at this point is not associated with a higher risk of tumor recurrence or progression in men with low-risk disease. A registry for prospective assessment and documentation of data from hypogonadal patients with a history of PCa on TRT is desirable. A well-defined indication for TRT in this group and a close follow-up schedule seem mandatory. As part of this schedule, regular measurements of PSA and free PSA may be implicated, as a recent study on the follow-up of patients with negative biopsies suggested [35]. TRT in cases of poorly differentiated PCa cell clones and advanced PCa must be critically evaluated. To date, neither the fact that the initiation of these cell clones in later stages of the disease is dependent on testosterone, nor that their propagation is purely testosterone driven, have been proven. Thus, additional molecular examinations within larger and prospectively designed studies are warranted. 


\section{References}

1 Zitzmann M, Faber S, Nieschlag E: Association of specific symptoms and metabolic risks with serum testosterone in older men. J Clin Endocrinol Metab 2006;91:4335-4343.

2 Huggins C, Hodges CV: Studies on prostatic cancer. I. The effect of castration, of estrogen, and of androgen injection on serum phosphatases in metastatic carcinoma of the prostate. Cancer Res 1941;1:293-297.

-3 Morgentaler A: Testosterone replacement therapy and prostate cancer. Urol Clin North Am 2007;34:555-563.

$\checkmark 4$ Morgentaler A: Testosterone therapy in men with prostate cancer: scientific and ethical considerations. J Urol 2013;189:S26-S33.

$\checkmark 5$ Morgentaler A, Rhoden EL: Prevalence of prostate cancer among hypogonadal men with prostate-specific antigen levels of $4.0 \mathrm{ng} /$ $\mathrm{ml}$ or less. Urology 2006;68:1263-1267.

$\checkmark 6$ Hoffman MA, DeWolf WC, Morgentaler A: Is low serum free testosterone a marker for high grade prostate cancer? J Urol 2000;163: 824-827.

7 Ribeiro M, Ruff P, Falkson G: Low serum testosterone and a younger age predict for a poor outcome in metastatic prostate cancer. Am J Clin Oncol 1997;20:605-608.

$>8$ Turo R, Tan K, Thygesen H, Sundaram SK, Chahal R, Prescott S, Cross WR: Diethylstilboestrol ( $1 \mathrm{mg})$ in the management of castration-resistant prostate cancer. Urol Int 2014, Epub ahead of print.

-9 Porcaro AB, Petrozziello A, Ghimenton C, Migliorini F, Sava T, Caruso B, Romano M, Cavalleri S, Artibani W: Associations of pretreatment serum total testosterone measurements with pathology-detected Gleason score cancer. Urol Int 2014;93:269-278.

$>10$ Fowler JE Jr, Whitmore WF Jr: The response of metastatic adenocarcinoma of the prostate to exogenous testosterone. J Urol 1981;126: 372-375.

11 Endogenous Hormones and Prostate Cancer Collaborative Group: Endogenous sex hormones and prostate cancer: a collaborative analysis of 18 prospective studies. J Natl Cancer Inst 2008;100:170-183.

-12 Marks LS, Mazer NA, Mostaghel E, Hess DL, Dorey FJ, Epstein JI, Veltri RW, Makarov DV, Partin AW, Bostwick DG, Macairan ML, Nelson PS: Effect of testosterone replacement therapy on prostate tissue in men with lateonset hypogonadism: a randomized controlled trial. JAMA 2006;296:2351-2361.

13 Labrie F: Blockade of testicular and adrenal androgens in prostate cancer treatment. Nat Rev Urol 2011;8:73-85.
14 Goldenberg SL, Koupparis A, Robinson ME: Differing levels of testosterone and the prostate: a physiological interplay. Nat Rev Urol 2011;8:365-377.

15 Tindall DJ, Rittmaster RS: The rationale for inhibiting 5alpha-reductase isoenzymes in the prevention and treatment of prostate cancer. J Urol 2008;179:1235-1242.

16 Page ST, Lin DW, Mostaghel EA, Hess DL, True LD, Amory JK, Nelson PS, Matsumoto AM, Bremner WJ: Persistent intraprostatic androgen concentrations after medical castration in healthy men. J Clin Endocrinol Metab 2006;91:3850-3856.

$>17$ Thigpen AE, Silver RI, Guileyardo JM, Casey ML, McConnell JD, Russell DW: Tissue distribution and ontogeny of steroid 5alpha-reductase isozyme expression. J Clin Invest 1993;92:903-910.

18 Silver RI, Wiley EL, Davis DL, Thigpen AE, Russell DW, McConnell JD: Expression and regulation of steroid 5alpha-reductase 2 in prostate disease. J Urol 1994;152:433-437.

19 Bartsch W, Klein H, Schiemann U, Bauer HW, Voigt KD: Enzymes of androgen formation and degradation in the human prostate. Ann NY Acad Sci 1990;595:53-66.

20 Labrie F, Luu-The V, Labrie C, Simard J: DHEA and its transformation into androgens and estrogens in peripheral target tissues: intracrinology. Front Neuroendocrinol 2001; 22:185-212.

21 Morote J, Orsola A, Planas J, Trilla E, Raventós CX, Cecchini L, Catalán R: Redefining clinically significant castration levels in patients with prostate cancer receiving continuous androgen deprivation therapy. J Urol 2007;178: 1290-1295.

22 Chang K-H, Li-R, Papari-Zareei M, Watumull L, Zhao YD, Auchus RJ, Sharifia N: Dihydrotestosterone synthesis bypasses testosterone to drive castration-resistant prostate cancer. Proc Natl Acad Sci U S A 2011;108: 13728-13733.

23 Kaufman JM, Graydon RJ: Androgen replacement after curative radical prostatectomy for prostate cancer in hypogonadal men. J Urol 2004;172:920-922.

24 Agarwal PK, Oefelein MG: Testosterone replacement therapy after primary treatment for prostate cancer. J Urol 2005;173:533-536.

25 Khera M, Colen J, Grober ED, Najari BB, Murthy L, Lamb DJ, Lipshultz LI: The safety and efficacy of testosterone replacement therapy following radical prostatectomy (abstract 1164). J Urol 2007;177(suppl):384.

26 Nabulsi O, Tal R, Gotto G, Narus J, Goldenberg L, Mulhall JP: Outcomes analysis of testosterone supplementation in hypogonadal men following radical prostatectomy (abstract 1244). J Urol 2008;179(suppl):426.
27 Khera M, Grober ED, Najari B, Colen JS, Mohamed O, Lamb DJ, Lipshultz LI: Testosterone replacement therapy following radical prostatectomy. J Sex Med 2009;6:1165-1170.

28 Sarosdy MF: Testosterone replacement for hypogonadism after treatment of early prostate cancer with brachytherapy. Cancer 2007; 109:536-541.

29 Daville HH, Arison CN, Hall MK, Salup R, Lockhart JL, Carrion RE: Analysis of the PSA response after testosterone supplementation in patients who have previously received management for their localized prostate cancer (abstract 1247). J Urol 2008;179(suppl): 428.

30 Morales A, Black AM, Emerson LE: Testosterone administration to men with testosterone deficiency syndrome after external beam radiotherapy for localized prostate cancer: preliminary observations. BJU Int 2009;103: 62-64.

31 Leibowitz RL, Dorff TB, Tucker S, Symanowski J, Vogelzang NJ: Testosterone replacement in prostate cancer survivors with hypogonadal symptoms. BJU Int 2010;105: 1397-1401.

32 Morgentaler A, Lipshultz LI, Bennett R, Sweeney M, Avila D Jr, Khera M: Testosterone therapy in men with untreated prostate cancer. J Urol 2011;185:1256-1261.

33 Morales A: Effect of testosterone administration to men with prostate cancer is unpredictable: a word of caution and suggestions for a registry. BJU Int 2011;107:1369-1373.

34 Dohle GR, Arver S, Bettocchi C, Kliesch S, Punab M, de Ronde W: Male hypogonadism. Guidelines on male Hypogonadism. EAU guidelines. http://www.uroweb.org/guidelines/ online-guidelines.

35 Yamamoto S, Kato M, Tomiyama Y, Amiya Y, Sasaki M, Shima T, Suzuki N, Murakami S, Nakatsu H, Shimazaki J: Management of men with a suspicion of prostate cancer after negative initial prostate biopsy results. Urol Int 2014;92:258-263.

36 Isbarn H, Fisch M, Huland H, Graefen M, Sommer F: Testosterone treatment after radical prostatectomy for pathologic organ-confined prostate cancer: results from a multiinstitutional study. J Urol 2010;183:e576e577.

37 Pastuszak AW, Pearlman AM, Godoy G, Miles BJ, Lipshultz LI, Khera M: Testosterone replacement therapy in the setting of prostate cancer treated with radiation. Int J Impot Res 2013;25:24-28. 